\title{
A atuação do enfermeiro junto à criança com câncer: cuidados paliativos
}

\author{
Nurses' work with children with cancer: palliative care \\ La actuación del enfermero junto al niño com cáncer: cuidados paliativos
}

\author{
Ana Claudia Moreira Monteiro'; Benedita Maria Rêgo Deusdará Rodrigues" \\ Sandra Teixeira de Araújo Pacheco ${ }^{\text {III }}$; Luana Sena Pimenta ${ }^{\text {IV }}$
}

\begin{abstract}
RESUMO: Objetivou-se conhecer a ação de cuidar do enfermeiro à criança com câncer em cuidados paliativos. Estudo qualitativo, desenvolvido com 14 enfermeiros lotados em enfermarias de onco-hematologia pediátrica de um hospital federal, localizado no município do Rio de Janeiro. A pesquisa foi realizada nos meses de junho e julho de 2011. A apreensão das falas se deu por meio de entrevistas semiestruturadas. Os dados foram submetidos à análise de conteúdo de Bardin. Como resultados, emergiram seis categorias analíticas: Dar conforto à criança; Cuidar da família; Atender às necessidades da criança; Proporcionar qualidade de vida à criança; Dar apoio espiritual, emocional e religioso; Estar mais próximo da criança, mostrando-se disponível. Em conclusão, os enfermeiros tratam das crianças em cuidados paliativos de forma singular, pautados na compreensão, no carinho e no respeito às suas necessidades e de sua família.
\end{abstract}

Palavras-Chave: Enfermagem oncológica; criança; oncologia pediátrica; cuidados paliativos.

\begin{abstract}
This qualitative study aimed to learn about the work of nurses caring for children with cancer in palliative care. The research was carried out during June and July 2011 with 14 nurses assigned to a pediatric hematology-oncology ward at a federal hospital in the municipality of Rio de Janeiro. Their statements were taken through semi-structured interviews. The data were submitted to Bardin content analysis, as a result of which, six analytical categories emerged: comforting the child; caring for the of family; meeting the child's needs; providing the child with quality of life; providing spiritual, emotional and religious support; and being closer to the child, and actively available. In conclusion, nurses treat children in palliative care in a unique manner guided by understanding, tenderness and respect for child's and the family's needs.

Keywords: Oncologic nursing; child; pediatric oncology; palliative care.

RESUMEN: Se objetivó conocer la acción de los cuidados de enfermería a niños con cáncer en cuidados paliativos. Estudio cualitativo realizado con 14 enfermeros actuantes en enfermerías de pediatría oncológica y hematologia de un hospital federal ubicado en Río de Janeiro - Brasil. La encuesta fue hecha en junio y julio de 2011. Los discursos fueron obtenidos por medio de entrevistas semiestructurada. Los datos fueron tratados por el análisis de contenido de Bardin. Como resultados, emergieron seis categorías: Dar confort al niño; Cuidar de la família; Satisfacer las necesidades del niño; Propiciar calidad de vida al niño; Proporcionar apoyo espiritual, emocional y religioso; Estar más próximo del niño, mostrándose disponible. En conclusión, los enfermeros tratan de los niños en cuidados paliativos singularmente, guiados por la comprensión, cariño y respeto a sus necessidades y de su familia.
\end{abstract}

Palabras Clave: Enfermería oncológica; niño; oncología pediátrica; cuidados paliativos.

\section{INTRODUÇÃO}

O câncer pediátrico é o conjunto de neoplasias que acometem os menores de 15 anos, geralmente são de origem embrionária, do sistema reticuloendotelial, do sistema nervoso central, do tecido conectivo e vísceras ${ }^{1}$.

O câncer infantil era considerado uma doença aguda com mau prognóstico. Atualmente, apresenta grande possibilidade de cura, com potencial aumento de sobrevida em aproximadamente $70 \%$ dos casos. Esse progresso se deu pela sofisticação dos estudos clínicos, da tecnologia de ponta e pelo atendimento multidisciplinar prestado a estas crianças com foco na humanização da assistência e preocupação da equipe com o paciente e sua família².

${ }^{\mathrm{I}}$ Mestre. Professora Substituta do Departamento de Enfermagem Materno-Iinfantil da Faculdade de Enfermagem da Universidade do Estado do Rio de Janeiro. Professora da Universidade Estácio de Sá. Rio de Janeiro, Brasil. E-mail: ana-burguesa@hotmail.com

IIProfessora Titular do Departamento de Enfermagem Materno-Infantil da Faculdade de Enfermagem da Universidade do Estado do Rio de Janeiro. Brasil. E-mail: benedeusdara@gmail.com

IIIProfessora Adjunta do Departamento de Enfermagem Materno-Infantil da Faculdade de Enfermagem da Universidade do Estado do Rio de Janeiro. Brasil. E-mail: stapacheco@yahoo.com.br

${ }^{\text {IV }}$ Mestranda pela Faculdade de Enfermagem da Universidade do Estado do Rio de Janeiro. Enfermeira Assistencial do Centro de Transplante de Medula óssea do Instituto Nacional de Câncer José de Alencar Gomes da Silva. Rio de Janeiro, Brasil. E-mail: luanaipb@yahoo.com.br

${ }^{v}$ Recorte da dissertação intitulada $\mathrm{O}$ cuidar do enfermeiro à criança hospitalizada, portadora de doença oncológica e fora de possibilidade de cura atual e sua família, Faculdade de Enfermagem da Universidade do Estado do Rio de Janeiro, 2012. 
Mesmo com o avanço tecnológico das terapêuticas atuais em oncologia pediátrica, muitas crianças não conseguem alcançar a cura, sendo assim implementados os cuidados paliativos.

Essas considerações iniciais possibilitaram refletir sobre a ação de cuidar do enfermeiro junto à criança em cuidados paliativos e indagar - que cuidados o enfermeiro realiza junto a essa criança?

O estudo objetivou conhecer as ações de cuidar do enfermeiro junto à criança com câncer em cuidados paliativos.

\section{REVISÃO DE LITERATURA}

O tratamento é especializado de acordo com o metabolismo da criança, a biologia tumoral e as abordagens terapêuticas, atingindo objetivos de cura até em doença disseminada, aumentando as taxas de sobrevida e minimizando os efeitos tardios do tratamento. $O$ sucesso terapêutico depende do controle local e sistêmico da doença e do suporte para os efeitos colaterais. Fazem parte do tratamento a quimioterapia, cirurgia, radioterapia e suporte clínico ${ }^{3}$.

A Organização Mundial da Saúde (OMS) define cuidados paliativos como uma abordagem que melhora a qualidade de vida dos pacientes e de seus familiares, frente à doença terminal, através da prevenção e do alívio do sofrimento por meio da identificação precoce, avaliação impecável e tratamento da dor e de outros problemas, físicos, psicossociais e espirituais ${ }^{4}$.

Em pediatria, o cuidado paliativo é definido como um programa organizado, voltado para a criança com vida limitada devido a uma doença atualmente incurável. Este se torna eficaz com o controle dos sintomas e quando são fornecidos apoio psicológico e espiritual para o paciente e suporte para a família na tomada de decisões².

Portanto, o enfermeiro que atua em cuidados paliativos deve desempenhá-los a partir de uma visão humanística, em que apesar da impossibilidade da cura, a sua relação com o paciente não deve deixar de acontecer, o que poderá trazer benefícios para ambos ${ }^{5}$.

\section{Metodologia}

Este descritivo e de abordagem qualitativa estudo foi desenvolvido nas enfermarias de oncohematologia do setor de internação pediátrica de um hospital público federal especializado em oncologia, localizado no município do Rio de Janeiro.

hospital em questão foi escolhido por ser referência nacional em oncologia e ter contribuído para inovações na assistência, pesquisa e qualificação profissional nessa área.

Participaram do estudo 14 enfermeiros que atenderam aos critérios de inclusão, ou seja, que realizavam cuidados diretos à criança com câncer em cuidados paliativos e sua família, que atuavam com essa clientela há mais de um ano e que apresentaram interesse em participar desta pesquisa.

Para contemplar os princípios éticos propostos para a realização da pesquisa com seres humanos, o projeto foi encaminhado ao Comitê de Ética e Pesquisa da instituição onde foi desenvolvida, sendo aprovado para sua realização com o Parecer no 043/11.

$\mathrm{O}$ anonimato dos sujeitos foi garantido com a utilização de um pseudônimo com o nome de flor de sua preferência, e todos foram esclarecidos quanto ao sigilo das informações coletadas, bem como ao direito à desistência de sua participação em qualquer fase da pesquisa. Após a leitura do Termo de Consentimento Livre e Esclarecido em voz alta, juntamente com o sujeito da pesquisa, e realizados os devidos esclarecimentos, foi solicitada a assinatura de cada termo, que foi datado e assinado pelos participantes.

A captação das falas deu-se com entrevistas semiestruturadas, realizadas no período de junho a julho de 2011, e foi orientada pela questão: Que ações de cuidar você desenvolve junto à criança em cuidados paliativos?

As entrevistas foram registradas em media player (mp3) para que não se perdesse nenhum conteúdo das falas e para que os entrevistados pudessem estabelecer uma relação mais direta e empática possível com a entrevistadora. Após a sua realização, foram transcritas para posterior análise.

A limitação do número de participantes observou a técnica de saturação de dados - foram encerradas quando os depoimentos começaram a se repetir.

O tratamento das informações obtidas, durante a entrevista, está alicerçado na análise de conteúdo de Bardin ${ }^{6}$ na modalidade temática, o que permitiu a codificação, desdobramento, agrupamento e síntese dos depoimentos, resultando em seis categorias analíticas: Dar conforto à criança; Cuidar da família; Atender às necessidades da criança; Proporcionar qualidade de vida à criança; Dar apoio espiritual, emocional e religioso; Estar mais próximo da criança, mostrando-se disponível.

\section{Resultados e Discussão}

\section{Dar conforto à criança}

Os enfermeiros entrevistados, ao realizarem o cuidado à criança, enfatizaram como primeira preocupação a necessidade de confortar esta criança diante do seu estado de adoecimento. A ação de confortar é uma possibilidade de dar benefícios, melhorando a condição da criança.

Dar um conforto. A gente dá um conforto. Então, o que eu faço é dar conforto, eu acho que é o principal para a criança. (Rosa) 
A primeira preocupação, quando eu cuido de crianças fora de possibilidade de cura, é proporcionar conforto, trazer à criança o máximo que eu posso de benefício para ela. (Lírio)

É importante destacar que, no cuidado paliativo, as medidas de suporte e conforto para o alivio do sofrimento, em virtude do avanço da doença, devem ser priorizadas visando ao bem-estar dessa criança ${ }^{2}$.

São estratégias de atenção da equipe que implicam o compromisso de oferecer um cuidado integral para melhorar a qualidade de vida da criança e dos seus familiares, destacando ações interativas que se fundamentam na relação de respeito e valorização do ser cuidado, procurando promover sistematicamente o que há de saudável para proporcionar o conforto ${ }^{7-9}$.

O objetivo dos cuidados paliativos pediátricos inclui metas físicas, psicológicas, educacionais, sociais e espirituais. Este cuidado visa melhorar a vida, diminuir o sofrimento e confortar o binômio criança e familia ${ }^{7-9}$.

\section{Atender às necessidades da criança}

Os enfermeiros reconhecem em sua ação de cuidar a importância de atender às necessidades da criança, não apenas, em relação aos sintomas apresentados, fazendo o diagnóstico do que elas precisam, mas, sobretudo para o que ela está sentindo naquele momento.

Uma criança considerada fora de possibilidade de cura, eu procuro conhecer a necessidade dela, naquele momento... [...] a gente tenta prestar um cuidado direcionado, em cima daquilo que o paciente precisa, diariamente. Hoje, pode ser importante uma conversa, o cuidado, a alimentação e o ombro mesmo, então procuro acompanhar, diagnosticar aquilo que aquela criança e a família precisam... [...] (Lírio)

Eu procuro saber qual a necessidade maior dela, naquele momento. Se é dor, ou se é, apenas, comer alguma coisa que ela está com vontade, ou se é ver alguém querido da família, que ela está com saudade. Então, é não achar que a necessidade dela, é o que a gente está avaliando no momento [...]. (Orquídea)

As ações de cuidado não devem somente se prender a cumprir atribuições técnicas de realização de procedimentos das práticas paliativas, mas também devem representar um elo, informando, orientando, dedicando um tempo para a família e para a criança; deixando-as expressar seus sentimentos, medos, anseios e esperanças; permitindo assim, que vivenciem e criem condições para o enfrentamento do processo ${ }^{10}$.

O cuidar envolve atitudes e ações simples como o toque, a escuta, estar sensível e perceptivo ao sofrimento do outro, ajudando-o na realização de suas atividades diárias, que a pessoa, nesse momento de vida, não pode realizar. Este precisa ser oferecido com carinho e atenção ${ }^{9,10}$.
Portanto, a assistência à criança com câncer deve abranger as necessidades físicas, psicológicas e sociais, incluindo personalização de assistência, promoção de cuidados atraumáticos, preparação de procedimentos e adoção de medidas para alívio da dor e desconforto, e incluir a família no processo de cuidar ${ }^{11-13}$.

Nesse sentido, percebe-se que os profissionais estão atentos ao caráter humanístico da implementação dos cuidados, avaliando e proporcionando o bem-estar para essa clientela, tentando sempre minimizar o sofrimento, realizando um cuidado individualizado e direcionado para cada criança.

Controle sempre da dor, do oxigênio, da parte gastrointestinal, porque conforme ela [a criança] vai tomando muita medicação, lá [na instituição] entram logo com opióide, ela [criança] vai ficar com uma constipação mais acentuada. Você tem que ver a parte da alimentação também, porque uma vez que ela já está com tudo alterado, ela não vai sentir fome, então não vai querer se alimentar. Aí, ou você passa uma sonda nessa criança ou você vai dar aquilo que ela mais gosta de comer [...], porque é um paciente oncológico, a criança sente muita dor, então a gente tenta minimizar essa dor [...] (Rosa)

Faço os remédios, para não ter dor, para não ter sofrimento. Passar uma sonda, se não está mais conseguindo se alimentar, para não sentir fome, eu acho que a gente tenta botar as necessidades de cada criança o mais estável possível, uma boa hidratação, uma boa analgesia, um suporte respiratório. (Rosa Vermelha).

A dor é considerada um dos mais constantes sintomas do câncer disseminado. O controle da dor é considerado um princípio básico para a qualidade de vida, mas em crianças o tratamento da dor é bastante crítico, em virtude da dificuldade de aferir a grandeza da dor nessa faixa etária ${ }^{2,7}$.

Os cuidados realizados por esses enfermeiros são centrados em procedimentos para minimizar a dor e o sofrimento, características dessa fase da doença. $\bigcirc$ que deixa os enfermeiros bastante sensibilizados é a intensidade de dor, buscando medidas para melhorá-la, sempre, na etapa que precede a cada procedimento. Desse modo, os cuidados paliativos são desenvolvidos por esses profissionais com a finalidade de proteger a dignidade da criança cuja vida tem valor mesmo sem perspectiva de cura ${ }^{3}$.

A dor vivenciada pelo paciente em cuidados paliativos é uma dor complexa, que inclui aspectos físicos, mentais e espirituais; diante da dor, o profissional deve valorizar a assistência holística, de maneira que a família possa se sentir contemplada em, seus anseios, principalmente, de que a criança não tenha dor ${ }^{10}$.

\section{Proporcionar qualidade de vida à criança}

Os enfermeiros entrevistados têm em vista a qualidade de vida das crianças que estão sob seus cuidados e referem, sempre, fazer o melhor que podem 
para dar mais vida aos dias que lhes restam, fazendo com que as crianças se sintam o melhor possível. Preocupam-se com as possibilidades da criança, realizando seus desejos.

Dar qualidade de vida para essas crianças, a gente tem que dar a melhor assistência... [...] vou fazer meu melhor. (Crisântemo)

Tentar melhorar a qualidade dos dias dela [...] Que eu acho que é importante, é que a gente tenta fazer, dar vida aos dias que restam para essas crianças... [...] Então, tentar dar, fazer com que esses dias sejam bons, é dar vida para esses dias, é dar uma qualidade, vida. Dias de alegria, dias de satisfação, dias sem dor, dias sem dispneia, um dia sem náusea, sem fadiga. (Violeta)

O objetivo dos cuidados paliativos é atingir a melhor qualidade de vida possível para os pacientes e suas famílias. Portanto, a manutenção da qualidade de vida e a valorização do tempo que resta a esses pacientes constituem-se nos princípios fundamentais dos cuidados paliativos oncológicos ${ }^{8-10}$

Na perspectiva da qualidade de vida, os enfermeiros ressaltam o brincar como algo que deve ser valorizado na sua ação de cuidar. Brincar promove a distração e possibilita o refúgio daquele momento especial que está vivendo.

É o bem-estar do paciente, acima de tudo, [...] que ele possa até mesmo brincar, porque tem muitos pacientes, fora de possibilidade de cura, [...] que conseguem brincar, entende? Então, você tem que investir nisso, ele tem que [...] brincar. (Girassol)

Ela deve brincar o máximo possível, interagir dentro das condições dela, ir para a brinquedoteca. (Tulipa)

Os recursos lúdicos são utilizados como recurso atenuante do difícil processo de hospitalização. Sua diversidade, mesmo não impedindo que a criança vivencie momentos dolorosos, possibilita que ela extravase sentimentos de raiva e hostilidade provocados pelo tratamento e por suas consequências. Além de contribuir para a aproximação entre todas as pessoas envolvidas no processo de hospitalização, contribui para a humanização e o enriquecimento do ambiente hospitalar. Para a criança, brincar é a principal atividade no hospital, pois a função lúdica é divertida e proporciona distração, alegria e prazer ${ }^{12,14}$.

As brincadeiras consistem no trabalho das crianças de todas as idades e assumem uma função primordial no seu desenvolvimento, sendo essenciais para o bem-estar mental, emocional e social ${ }^{14}$.

O brincar torna a hospitalização mais suportável e menos traumática para a criança, produz relaxamento, proporciona um meio para aliviar tensão e expressar sentimentos, diminui o estresse da separação e os sentimentos de estar longe de casa, ajudando a criança a sentir-se mais segura em um ambiente estranho ${ }^{14}$.
Portanto, o brincar é uma necessidade tanto da criança saudável quanto em processo de adoecimento, sendo importante para seu desenvolvimento. Através do brincar, a criança cria, se socializa, aprende, representa papéis. Para a criança com câncer, o brincar facilita o enfrentamento de situações de difícil controle, tais como: necessidade de internação hospitalar, o afastamento da família, da escola e dos amigos, procedimentos invasivos e dolorosos. A necessidade de brincar sempre existe mesmo na hospitalização da criança $a^{15}$.

\section{Dar apoio espiritual, emocional e religioso}

Os enfermeiros entrevistados enfocam a importância do apoio espiritual, emocional e religioso como uma forma de cuidado humano, que é inerente ao ser, e como essa ajuda diferencia a essência de cuidar. Todos apontam que este apoio traz mais aceitação, tranquilidade e como o poder da oração pode acalentar, nessas horas de desestruturação emocional.

Suporte emocional; se precisar, espiritual, falar sobre religião, mesmo que não seja a minha [...] a gente tem que dar todo apoio. Não faço nada, se eu tiver que ficar do lado de uma criança a noite inteira, ficar ali, dando suporte emocional... [...] inclusive quando eles querem que vá alguém da religião deles para poder dar um conforto espiritual. E acho que apoio emocional não é só psicologia, acho que é a enfermagem estar ali. (Rosa)

Às vezes, orava por ele, pegava sua mão, e eles apertavam tanto, e te agradeciam muito... [...], mas também, se você tocar nele e falar uma palavra amiga, independente da religião, se ele aceitar, ele consegue superar esse momento de medo... [...] então, eu acho que sempre tem um fundamento; ali, ele sempre tem alguma coisa para passar para você, por mais que ele diga: tia, eu vou morrer segura na minha mão. Ele falou isso comigo, eu segurei. Tia ora por mim, tia não deixa eu morrer. [...] você se fortalece com aquilo, você consegue dar mais esperança para mãe e para eles... [....] (Rosa Vermelha)

Qualidade de vida define todos os aspectos de bem-estar do paciente, inclusive a saúde espiritual. Assim, visando abranger as dores psíquicas e espirituais, faz-se necessário considerar as expressões religiosas do paciente, as quais exercem um papel fundamental na formação integral do indivíduo?.

O mundo vivido por todos os homens mostra a necessidade de cada um se sentir apto a fornecer apoio ao outro em situação de desespero, procurando subsídios na fé, no amor, na caridade, conforme o legado humanitário. Nesse mundo intersubjetivo, acontece a interação entre o enfermeiro, a criança e a família, constituindo um nós, que permite a compreensão e o consentimento mútuos que ocorrem na situação comum de dar e receber apoio, seja no âmbito emocional, espiritual ou religioso ${ }^{16}$. 


\section{Estar mais próximo da criança mostrando-se disponível}

Os entrevistados falaram sobre a importância da disponibilidade, do toque, do carinho, do abraço como um suporte para a criança num momento tão difícil, enfatizando que o carinho, em seu caráter subjetivo, tem um efeito moral significativo, e que estar presente, junto à criança, torna-a mais confiante para enfrentar o que está por vir.

Eu tento estar sempre presente, assim, eu tento sempre tirar um espaço do meu plantão, do meu dia a dia, num cuidado com aquela criança. Não é porque a gente não tem nada para fazer para curar a doença, que a gente não possa fazer nada pela criança... [...] E, também, converso com a criança, mesmo sem ela interagir comigo, porque eu acredito, assim, que ela possa estar me ouvindo, que a gente não sabe até que ponto, essa criança está consciente, ou até que ponto ela não está... [...] (Orquidea).

E algumas crianças precisavam da gente, ali, 24 horas do lado delas, e a gente ficava. A maioria dos profissionais que trabalha com oncologia tem essa disponibilidade e sabe que vai ser necessário o profissional, ali, do lado. Sempre, orientando, ajudando, porque só a mãe não consegue, e, às vezes, eles ficam perdidos, precisam de ajuda de um profissional qualificado, dentro da enfermagem. [...] a gente está, ali, o tempo todo, acho que tanto o enfermeiro quanto o técnico, ficar, ali, conversando com a mãe e com a criança, tentando animar, tentando melhorar o astral. (Rosa)

A presença vivida na relação face a face, que ocorre através de um voltar-se intencionalmente da equipe de enfermagem para a criança e seu familiar na atitude de estarem próximos e se mostrarem disponíveis para aquelas crianças para promover uma intercomunicação direta e intersubjetiva. Esse relacionamento entre o enfermeiro e essas pessoas está pautado num envolvimento emocional entre semelhantes, é resultado de uma experiência direta vivida entre eles ${ }^{16}$.

Os enfermeiros ressaltam o cuidado e sua influência na assistência prestada à criança como um conviver em seu cotidiano que reforça o seu lado humano frente às situações por ele vividas.

\section{Cuidar da família}

Ao cuidar de uma criança em cuidados paliativos, os enfermeiros inserem os familiares nesse cuidar, através de atitudes como uma conversa, um abraço, um ombro que possibilitam consolo para o sofrimento causado por uma doença tão difícil. Alguns desses profissionais revelaram que ao ter em vista o cuidar dessa família, o fazem escutando, conhecendo seus problemas, tranquilizando-os, estando junto, procurando amenizar um pouco aquele momento.
Eu tento que minha assistência seja focada [também] nos pais. Não só as crianças, porque eles também precisam do nosso cuidado, e cabe à gente focar nossa assistência, muito mais nos pais, porque saber lidar com isso não é fácil. (Crisântemo)

Você vai lá, conversa com o familiar, tenta consolar, tenta minimizar o sofrimento dele, hoje ele está sofrendo, porque sabe que amanhã vai ser complicado, porque o filho, a criança, já vai entrar em tratamento paliativo. [...] Então eu tento dar o maior apoio para essa família. Às vezes, você vê que eles [familiares] vão ao posto de enfermagem, e nem querem perguntar nada, só querem atenção, porque estão sozinhos, estão numa escuridão, e só querem um pouco de luz, Aí, você dar um ombro amigo, ajuda bastante. (Rosa)

A família é uma parte importante desse contexto, participando ativamente nos cuidados paliativos, pois está o tempo todo junto com a criança, causando, às vezes, desequilíbrios no âmbito familiar, em virtude de ter centralizado toda a atenção na criança que adoeceu, e que não tem mais possibilidades de cura, trazendo para si uma grande sensação de perda ${ }^{2}$.

A escuta sensível dos familiares e da criança propicia um ambiente terapêutico, de carinho e atenção e uma comunicação franca, de confiança, solidariedade, de cuidado, preocupando-se em apoiar e estar presente, controlando os sintomas e aliviando o sofrimento ${ }^{17-22}$.

Assim, a inserção da família, durante todo o processo de assistência, torna-se fundamental para os cuidados necessários à criança, e, também, para ter espaço de expressão e escuta do seu sofrimento e aprendizado para lidar com o problema ${ }^{17-22}$.

Entre as limitações do estudo, destaca-se a complexidade do fenômeno da intersubjetividade ao compartilhar o sentir com o outro. Vale registrar que os propósitos dos estudos qualitativos não visam a generalização dos achados.

\section{ConClusão}

Da análise dos depoimentos dos enfermeiros surgiram as categorias: Dar conforto à criança; Cuidar da família; Atender às necessidades da criança; Proporcionar qualidade de vida à criança; Dar apoio espiritual, emocional e religioso; Estar mais próximo da criança, mostrando-se disponível.

$\mathrm{O}$ estudo possibilitou entender que, diante da criança em cuidados paliativos e sua família, o modo de agir desses enfermeiros se pauta em atitudes de promoção de conforto e bem-estar, através do carinho e atenção, favorecendo a realização de desejos, desde que não lhe cause prejuízos, bem como o apoio emocional e espiritual, tão importantes nesse momento. 
No enfoque do cuidado, pode-se enfatizar a escuta sensível, que é realizada pelos enfermeiros, no apoio emocional à criança e à sua família, em que se mostram solícitos às indagações e procuram escutar essa família, que se encontra em desespero ante um desfecho inevitável, mediante o consolo e o acolhimento.

Os enfermeiros entrevistados se comprometem com o cuidado à criança em cuidados paliativos, mostrando-se disponíveis e procurando fazer o melhor possível para essa clientela, pois mesmo que não seja possível obter a cura, a criança ainda tem vida e precisa ser cuidada. Nesse momento, o carinho e a atenção são evidenciados no cuidado, promovendo conforto e qualidade do tempo existencial que resta ao paciente, captando suas necessidades para atendê-lo de modo apropriado.

\section{REFERÊNCIAS}

1.Braga PE, Latorre MRDO, Curado MP. Câncer na infância: analise comparativa da incidência, mortalidade e sobrevida em Goiânia (Brasil) e outros países. Cad Saúde Pública. 2002; 18: 33-44.

2.Camargo B, Kurashima A. Cuidados paliativos em oncologia pediátrica. São Paulo: Lemar; 2007.

3.Camargo BLF. Pediatria oncológica: noções fundamentais para o pediatra. São Paulo: Lemar; 2000.

4. World Health Organization. National cancer control programmes: policies and managerial guidelines. $2 \mathrm{nd}$ ed.Genese (Swi): World Health Organization; 2002.

5.Santos MCL, Pagliuca LMF, Fernandes AFC. Cuidados paliativos ao portador de câncer: reflexões sob o olhar de Paterson e Zderad. Rev Latino-Am Enfermagem. 2007; 2 (2): $10-6$.

6.Bardin L. Análise de conteúdo. São Paulo: Edições 70; 2011.

7.Monteiro ACM, Rodrigues BMRD, Pacheco STA. O enfermeiro e o cuidar da criança com câncer sem possibilidade de cura atual. Esc Anna Nery. 2012; 16: 741-6. 8.Foster TL, Lafond DA, Reggio C, Hinds PS. Pediatric palliative care in childhood cancer nursing: from diagnosis to cure or end of life. Seminars in Oncology Nursing. 2010; 26: 205-21.

9.Bernadá M, Dall'Orso P, Fernández G, Le Pera V, González E, Bellora R, et al. Abordaje del niño con una enfermedad pasible de cuidados paliativos Arch Pediatr Urug. 2010; 81: 239-47.

10.Santos LMS, Araujo JS, Lima Júnior RM, Sousas RF, Conceição VM, Santana, ME. Cuidados paliativos para a criança com câncer: reflexões sobre o processo saúde-doença Rev Bras Pesq Saúde. [periódico de in- ternet]. 2013 [citado em 07 fev 2014]; 15(3): 130-8. Disponível em : http://periodicos.ufes.br/RBPS/article/ view/6335/4669.

11.Silva RS, Amaral JB, Malagutti W. Enfermagem em cuidados paliativos: cuidando para uma boa morte. São Paulo: Martinari; 2013.

12.Silva AF, Issi HB, Motta MGC. A família da criança oncológica em cuidados paliativos: o olhar da equipe de enfermagem. Cienc Cuid Saude [periódico de internet] 2011 [citado em 02 fev 2014 ]; 10: 820-7. Disponível em: http://periodicos.uem.br/ojs/index.php/CiencCuidSaude/ article/view/18328/pdf

13.Avanci BS, Carolindo FM, Góes FGB, Cruz Netto NP. Cuidados paliativos à criança oncológica na situação do viver/morrer: a ótica do cuidar em enfermagem. Esc Anna Nery. [periódico de internet] 2009 [citado em 02 fev 2014]; 13: 708-16. Disponível em: http://www. scielo.br/pdf/ean/v13n4/v13n4a04.pdf

14.Pedrosa AM, Monteiro H, Lins K, Pedrosa F, Melo C. Diversão em movimento: um projeto lúdico para crianças hospitalizadas no serviço de oncologia pediátrica do Instituto Materno-Infantil Prof. Fernando Figueira, IMIP. Rev Bras Saude Mater Infant. [periódico de internet] 2007 [citado em 02 fev 2014 ]; 7: 99-106. Disponível em: http://www.scielo.br/pdf/rbsmi/v7n1/a12v07n1.pdf. 15.Costa TF, Ceolim MF. A enfermagem nos cuidados paliativos à criança e adolescente com câncer: revisão integrativa de literatura Rev Gauch Enferm.2011, 31: 776-84. 16.Hockenberry MJ, Wilson D, Wilkestein ML. WongFundamentos de enfermagem pediátrica. Rio de Janeiro: Elsevier; 2007.

17.Silva LF, Cabral IE, Christoffel MM. O brincar na vida da criança com câncer em tratamento ambulatorial: (im) possibilidades de desenvolvimento e contribuições da enfermagem Acta Paul Enferm. 2010; 23: 334-40.

18. Wagner H. Sobre fenomenologia e relações sociais/ Alfred Schütz. Petrópolis(RJ): Vozes; 2012.

19.Carvalho CSU. A necessária atenção à família do paciente oncológico. Revista Brasileira de Cancerologia 2008; 54(1): 87-96

20.Diefenbach GDF, Motta MGC. O cuidar em enfermagem: família e criança com dor oncológica. Cogitare Enferm. [periódico de internet] 2012 [citado em 02 fev 2014]; 17: 458-63. Disponível em: http://ojs.c3sl.ufpr.br/ ojs2/index.php/cogitare/article/viewFile/24752/19035

21. Brito FM, Costa ICP, Andrade CG, Lima KFO, Costa SFG, Lopes MEL. Espiritualidade na iminência da morte: estratégia adotada para humanizar o cuidar em enfermagem. Rev enferm UERJ. 2013; 22: 483-90.

22.Gomes GC, Xavier DM, Mota MS, Salvador MS, Silveira RS, Barlem ELD. Dando notícias difíceis à família da criança em situação grave ou em processo de terminalidade. Rev enferm UERJ. 2014; 22: 347-52. 